\title{
Obstetric gel shortens second stage of labor and prevents perineal trauma in nulliparous women: a randomized controlled trial on labor facilitation
}

\author{
Andreas F. Schaub1, Mario Litschgi ${ }^{2}$, Irene \\ Hoesli $^{3}$, Wolfgang Holzgreve ${ }^{3}$, Ulrich Bleul ${ }^{4}$ \\ and Verena Geissbühler ${ }^{5, *}$ \\ ${ }^{1}$ Happy Child Birth Holding AG Basel, Switzerland \\ 2 Women's Hospital, Kantonsspital Schaffhausen, \\ Switzerland \\ ${ }^{3}$ Department of Obstetrics, University Hospital Basel, \\ Basel, Switzerland \\ ${ }^{4}$ Clinic of Reproductive Medicine, Vetsuisse-Faculty, \\ University Zuerich, Switzerland \\ ${ }^{5}$ Kantonsspital Frauenfeld, Frauenfeld, Switzerland
}

\begin{abstract}
Objective: To determine whether the obstetric gel shortens the second stage of labor and exerts a protective effect on the perineum.

Method: A total of 251 nulliparous women with singleton low-risk pregnancies in vertex position at term were recruited. A total of 228 eligible women were randomly assigned to Group A, without obstetric gel use, or to Group B, obstetric gel use, i.e., intermittent application into the birth canal during vaginal examinations, starting at the early first stage of labor (prior to $4 \mathrm{~cm}$ dilation) and ending with delivery.

Results: A total of 183 cases were analyzed. For vaginal deliveries without interventions, such as C-section, vaginal operative procedure or Kristeller maneuver, obstetric gel use significantly shortened the second stage of labor by $26 \min (30 \%)(P=0.026)$, and significantly reduced perineal tears $(P=0.024)$. First stage of labor and total labor duration were also shortened, but not significantly. Results did not show a significant change in secondary outcome parameters, such as intervention rates or maternal and newborn outcomes. No side effects were observed with obstetric gel use.

Conclusion: Systematic vaginal application of obstetric gel showed a significant reduction in the second stage of labor and a significant increase in perineal integrity. Future studies should further investigate the effect on
\end{abstract}

\footnotetext{
${ }^{*}$ Corresponding author:

Verena Geissbühler, MD

Kantonsspital Frauenfeld

Pfaffenholzstrasse 4

8501 Frauenfeld

Switzerland

E-mail: vgeissbuehler@bluewin.ch
}

intervention rates and maternal and neonatal outcome parameters.

Keywords: Labor facilitation; obstetric gel; perineal laceration; second stage of labor.

\section{Introduction}

In the past few decades, a causal link between birth injury and postpartum pelvic floor dysfunction has been established [13]. Vaginal birth increases 4-11 times the risk of developing pelvic organ prolapse [16], and 2.7 times the risk of stress urinary incontinence [21]. Perineal trauma in childbirth can result in urinary and fecal incontinence, painful intercourse, and persistent perineal pain [12]. Obstetric factors responsible for anal sphincter rupture and fecal incontinence have been studied and include forceps delivery, episiotomy and prolonged second stage [8, 9, 13, 18, 24]. Several other studies also documented a prolonged second stage as a risk factor for pelvic floor injury [6, 9]. Although the duration of second stage labor is not associated with impaired neonatal outcome, it is associated with increased maternal morbidity and operative delivery rates in nulliparous women [6]. In multiparous women, an association between the duration of second stage of labor and increased maternal and neonatal morbidity was found: a duration exceeding $2 \mathrm{~h}$ increased the risk for operative vaginal delivery, a duration exceeding $3 \mathrm{~h}$ increased the risk for perineal lacerations and undesirable neonatal outcomes [7].

With the goal of optimizing labor outcomes, many techniques have been investigated: nulliparous women decreased their trauma risk by undergoing perineal massage a few weeks before delivery [10]. Evidence from randomized clinical trials (RCT) has shown that avoiding episiotomy protects the perineal integrity [5, 10], while the upright maternal position during the second stage of labor did not affect overall perineal trauma [10]. The procedure of a perineal massage with a lubricant at late second stage had been previously investigated, and showed a reduction in the duration of the second stage without showing a significant effect on perineal integrity $[3,23]$.

The ideal management of labor should maximize the probability of vaginal delivery and minimize the risk for maternal and neonatal morbidity. The aim of this randomized controlled trial was to investigate the effects of a specially designed obstetric gel, Dianatal ${ }^{\circledR}$ (MPC INTER- 
NATIONAL S.A., 26, Boulevard Royal, L-2449 Luxembourg), on labor outcomes, focusing on the length of the second stage of labor and on perineal integrity. In contrast to the previous investigations using "classical perineal massage" with a lubricant in the late second stage of labor [3,23], the goal of this investigation was to optimize the lubrication effect on vaginal delivery not only by using a specially developed obstetric gel containing polyacrylic acid as a bioadhesive agent, but also by starting intermittent intravaginal application during the first stage of labor.

\section{Materials and methods}

This study was carried out at two centers in Switzerland between October 2005 and October 2006: the Cantonal Women's Hospital at Frauenfeld (1200 births per year) and the Cantonal Women's Hospital at Schaffhausen (600 births per year). During this period, no relevant changes occurred in the clinical environment, professional staff or patient population. Both institutions are recognized educational institutions. In both institutions similar routine care was used: delivery was attended by a midwife and a doctor, the vaginal exams and application of gel were usually done by midwives, and episiotomy was used selectively.

The study was performed as a randomized, controlled, multicenter parallel group trial in nulliparous women (computer randomization with use of envelopes). Due to the type of procedure, it was impossible to carry out a blinded or placebo controlled study.

Patients were randomly assigned to either Group A (standard of care in accordance with the established guidelines of the department without obstetric gel use) or to Group B (standard of care in accordance with the established guidelines of the department, plus vaginal application of the obstetric gel according to the study protocol). For the analysis of outcome parameters, Groups A and B have been further divided into the following subgroups in order to eliminate intentional influences on labor durations:

- Group A-l: births from an occipito-anterior position without interventions, such as cesarean section, vaginal operative procedures, or Kristeller manouver; no obstetric gel use;

- Group B-I: births from an occipito-anterior position without interventions, such as cesarean section, vaginal operative procedures, or Kristeller manouver: with obstetric gel use;

- Group A-II: births from an occipito-anterior position without interventions, such as cesarean section or vaginal operative procedures: no obstetric gel use

- Group B-Il: births from an occipito-anterior position without interventions, such as cesarean section or vaginal operative procedures: with obstetric gel use

The Study Protocol, the Investigator's Brochure, the Patient Information, and the Informed Consent Form were submitted to three Cantonal Ethics Committees for review and approval: the local State Ethics Committee of both Basel Cantons (EKBB), the Ethics Committee of Canton Thurgau and the Ethics Committee of Canton Zürich (responsible for Schaffhausen). The written approvals from the three Ethics Committees were sent for final approval to the Swiss Authorities, Swissmedic, for notification. The written approval of the Ethics Committee and the approval notification from Swissmedic were sent to the sponsor Happy Child Birth Holding and Foundation before the study commenced.

Verbal and written consent was obtained in German by the clinical midwife. The patient record was marked indicating consent, refusal or ineligibility for the study. At hospital admission for delivery, the eligible women were checked to see if they fulfilled the inclusion criteria. If so, they were then asked if they still wished to participate in this study.

This study was carried out in accordance with the recommendations of the Declaration of Helsinki, adopted by the $18^{\text {th }}$ WMA General Assembly Helsinki, Finland, June 1964, and lastly amended by the $52^{\text {nd }}$ WMA General Assembly, Edinburgh, Scotland, October 2000.

\section{Inclusion and exclusion criteria}

The following were defined as inclusion criteria: age between 18 and 40 years; signed written informed consent; intended vaginal delivery; nulliparous state; singleton baby in vertex presentation (finally evaluated post partum); estimated birth weight between $2000 \mathrm{~g}$ and $4500 \mathrm{~g}$ (clinically or by sonography); and low risk pregnancy at term (37-42 weeks' gestation). The following were defined as exclusion criteria: contraindications for vaginal delivery; indications for an amniotic infection; indications of fetal distress; prolonged rupture of the membranes ( $>24 \mathrm{~h}$ ); suspected fetal malformations; indications of cephalopelvic disproportion; severe concomitant maternal disease; women performing water births.

\section{Study outcome parameters}

The following primary outcome parameter was assessed: reduction in the length of the second stage of labor (full dilation of the cervix until birth of the newborn). The secondary outcome parameters were reduction in the length of the first stage of labor (cervical dilation between $4 \mathrm{~cm}$ and $10 \mathrm{~cm}$ ); reduction of perineal lacerations; differences in newborn outcomes (Apgar score 1, 5 and 10 min after birth; umbilical cord pH); differences in obstetric interventions (cesarean section, vaginal operative interventions, episiotomies). Likewise, maternal and newborn side effects due to the obstetric gel were also investigated.

\section{Obstetric gel specifications}

A specially-designed sterile obstetric gel was used for this investigation. The obstetric gel is based on cross-linked polyacrylic acid, hydroxyethylcellulose and propylene glycol, and is free of preservatives. A steam vaporization process was used for sterilization. Farco Pharma GmbH Köln/Klosterfrau Berlin GmbH, Germany, manufactured the product in accordance with GMP (good manufacturing practice) regulations. Prior to this study, extensive biocompatibility studies were performed at Toxikon Europe, Leuven, Belgium, according to FDA (food and drug administration) standards. These studies showed a safe biocompatibility profile with no indications for maternal or newborn hazards. The obstetric gel received the CE (Communauté Européenne) Trade Mark during the course of the study (Medical Device Type I, December 2005). 
The obstetric gel has the following special properties that are mandatory for use in obstetrics: high mucoadhesive activity; high viscosity; electric conductivity; sterile; and non-allergenic. The special properties should also guarantee its safe use in the obstetric environment, with the potential unforeseeable need to switch over to cesarean section and/or perform electrosurgery.

The obstetric gel was supplied by HCB (happy child birth) Happy Child Birth Holding and Foundation in sterile single-use, packed $11 \mathrm{~mL}$ syringes, and stored at room temperature.

\section{Gel application method}

In study Group B, the obstetric gel was intermittently applied into the birth canal during vaginal examination, beginning with the first vaginal examination. The gel administration started in the early first stage of labor (prior to $4 \mathrm{~cm}$ cervical dilation) and ended with the delivery of the newborn. $3-5 \mathrm{~mL}$ of gel were evenly distributed in the vagina at each examination using a sterile glove (maximal duration: $30 \mathrm{~s}$ ). The administration of the gel was generally instructed, but not specially trained. The gel was applied manually into the birth canal without a vaginal applicator. No perineal massage was performed. After delivery of the newborn's head, the mouth-nose region was cleaned with a dry towel.

\section{Data management}

Data management was carried out under the supervision of the Division of Clinical Pharmacology and Toxicology, University Clinic of Basel, Switzerland. Randomization, design and preparation of the case report forms were carried out by Analytical International $\mathrm{GmbH}$, Lörrach, Germany. Data entry was performed in duplicate by two different people. During entry, data were checked for completeness and plausibility. If the two data sets showed discordant values, entries were again checked against the raw data and consolidated.

\section{Statistical analysis}

The durations of the first and second stages of labor were compared between the study groups by analysis of variance (ANOVA), with age, body mass index, birth weight of neonate, and center as covariates. Comparisons were performed using SPSS for Windows software [Version 11.0 (Chicago, USA)]. The level of significance was set at $\mathrm{P}=0.05$. For odds ratio calculations in perineal lacerations, the software Graph Pad Instat Version 3.06 (GraphPad Software Inc., San Diego, USA) was also used.

Secondary outcome parameters were compared between the groups by analysis of variance (continuous variables), nonparametric Mann-Whitney $U$-test (scores) and $\chi^{2}$-test or Fisher's exact test, as appropriate.

All parameters have been analyzed descriptively: raw data have been tabulated by treatment, and graphical representations have been made.

\section{Power analysis with regard to sample size}

The primary outcome parameter was defined as the reduction in the length of the second stage of labor. The expected effect was a $50 \%$ reduction in the difference of labor duration between nulliparous and multiparous women. In the following, recently- established and widely-accepted labor duration times are given [2]:

Overall ethnical groups length of labor times are:

- Nulliparous women: labor stage 1: $462 \pm 354 \min (S D: 76.6 \%)$ $(n=347) / /$ labor stage 2: $53 \pm 47 \mathrm{~min}(\mathrm{SD})(\mathrm{n}=556) / /$ total: $515 \mathrm{~min}$;

- Multiparous women: labor stage 1: $342 \pm 240 \mathrm{~min}$ (SD: $70.4 \%)(n=602) / /$ labor stage 2: $17 \pm 20 \mathrm{~min}(\mathrm{SD})(\mathrm{n}=917) / /$ total: $359 \mathrm{~min}$

- Delta/2: $(53-17 \mathrm{~min}) / 2=18$

In order to ensure an $80 \%$ power of detecting a difference in means of $18 \mathrm{~min}$ (the difference between a Group 1 mean of $53 \mathrm{~min}$ and a Group 2 mean of $35 \mathrm{~min}$ ), a sample size of 87 in each group was estimated, assuming that the common standard deviation is 42 min (corresponding to $80 \%$ ) using a two group $t$-test with a 0.05 two-sided significance level (calculated by nQuery Advisor 5.0) (Statistical Solutions, Saugus, USA). To account for drop-outs, $n=100$ for both treatment groups was chosen.

\section{Results}

A total of 251 women were recruited in both study centers; 228 proved eligible for study participation, and were randomly assigned to the two study groups. From this group, women deciding for a waterbirth were excluded from the analysis, and the resulting 183 cases were analyzed (Table 1). Of these, 89 cases were treated according to the established standards of care of the study centers and were assigned to Group A, and 94 cases were treated with the obstetric gel according to the application instructions, and in accordance with the established standards of care, and were assigned to Group B. There was no statistically significant difference in the proportion of treatment groups per center. There was no statistically significant difference in the demographic and outcome parameters of the mothers and neonates between the study groups (Table 2). Study groups did not differ significantly in the prevalence of occipito-anterior, occipito-posterior or deflexion position. Likewise, there was no statistically significant difference in the number of cesarean sections, vacuum and forceps extractions, Kristeller maneuvers, elective amniotomy or epidural anesthesia between the study groups.

To evaluate the impact of the obstetric gel use on labor facilitation, our focus was set on the subgroup analysis

Table 1 Treatment by study centers Schaffhausen (SH) and Frauenfeld (FF).

\begin{tabular}{llrr}
\hline & \multicolumn{2}{l}{ Center } & Total \\
\cline { 2 - 3 } & SH & FR & \\
\hline Treatment & & & \\
Group A: no gel & 22 & 67 & 89 \\
Group B: with gel & 27 & 67 & 94 \\
Total & 49 & 134 & 183 \\
\hline
\end{tabular}


Table 2 Demographic and outcome parameters of mothers and neonates.

\begin{tabular}{|c|c|c|c|c|}
\hline & $\mathrm{n}$ & Mean & SD & P-value \\
\hline \multicolumn{5}{|c|}{ Maternal age (years) } \\
\hline Group A & 89 & 28.6 & 5 & \multirow[t]{2}{*}{0.972} \\
\hline Group B & 94 & 28.6 & 5.27 & \\
\hline \multicolumn{5}{|c|}{ Gestation (days) } \\
\hline Group A & 89 & 280.6 & 7.55 & \multirow[t]{2}{*}{0.857} \\
\hline Group B & 94 & 280.4 & 6.95 & \\
\hline \multicolumn{5}{|c|}{ Maternal weight (kg) } \\
\hline Group A & 87 & 78.6 & 11.42 & \multirow[t]{2}{*}{0.379} \\
\hline Group B & 94 & 77.1 & 11.5 & \\
\hline \multicolumn{5}{|c|}{ Cervix on admission (cm) } \\
\hline Group A & 89 & 1.5 & 0.97 & \multirow[t]{2}{*}{0.891} \\
\hline Group B & 94 & 1.5 & 0.94 & \\
\hline \multicolumn{5}{|c|}{ Maternal length (cm) } \\
\hline Group A & 87 & 165.2 & 6.98 & \multirow[t]{2}{*}{0.482} \\
\hline Group B & 94 & 165.9 & 5.98 & \\
\hline \multicolumn{5}{|c|}{ Neonatal weight (g) } \\
\hline Group A & 89 & 3384.9 & 388.15 & \multirow[t]{2}{*}{0.437} \\
\hline Group B & 94 & 3433.7 & 454.9 & \\
\hline \multicolumn{5}{|c|}{ Neonatal head circ. (cm) } \\
\hline Group A & 89 & 35.1 & 1.15 & \multirow[t]{2}{*}{0.197} \\
\hline Group B & 94 & 34.9 & 1.38 & \\
\hline \multicolumn{5}{|c|}{$\begin{array}{l}\text { Maternal complications due to } \\
\text { obstetric gel use }\end{array}$} \\
\hline Group A & 89 & 0 & & \\
\hline Group B & 94 & 0 & & \\
\hline \multicolumn{5}{|c|}{$\begin{array}{l}\text { Newborn complications due to obstetric } \\
\text { gel use (neonatal infection, transfer } \\
\text { to NICU) }\end{array}$} \\
\hline Group A & 89 & 0 & & \\
\hline Group B & 94 & 0 & & \\
\hline \multicolumn{5}{|c|}{ Apgar score $1 \mathrm{~min}$} \\
\hline Group A & 37 & 8.75 & & \multirow[t]{2}{*}{0.028} \\
\hline Group B & 37 & 8.35 & & \\
\hline \multicolumn{5}{|c|}{ Apgar score 5 min } \\
\hline Group A & 37 & 9.75 & & \multirow[t]{2}{*}{0.024} \\
\hline Group B & 37 & 9.45 & & \\
\hline \multicolumn{5}{|c|}{ Apgar score $10 \mathrm{~min}$} \\
\hline Group A & 37 & 9.89 & & \multirow[t]{2}{*}{0.546} \\
\hline Group B & 37 & 9.84 & & \\
\hline
\end{tabular}

of Groups A-I and B-I. The following results are from the comparison of Group A-I to Group B-I (Tables 3 and 4).

Stage 1 labor duration was $208.92 \pm 20.63$ (SEM) min (median $165.0 \mathrm{~min}$ ) in Group A-I, and 186.35 \pm 22.67 (SEM) min (median 140.0 min) in Group B-I. Stage 2 labor duration was $88.14 \pm 9.95$ (SEM) min (median $78.0 \mathrm{~min}$ ) in Group A-I, and 61.78 \pm 5.98 (SEM) min (median $56.0 \mathrm{~min}$ ) in Group B-I. A significant reduction in stage 2 duration by $26.4 \mathrm{~min}$ or $30 \%$ was observed in Group B-I compared to Group A-I; $P=0.026$ (Figure 1). The mean total labor duration (stages 1 and 2) was $297.05 \pm 21.42$ (SEM) min (median $284.0 \mathrm{~min}$ ) in Group A-I, and 248.14 \pm 25.66 (SEM) min (median $202.0 \mathrm{~min}$ ) in Group B-I. As shown in Table 2, Apgar scores after 1 min [8.75 (A-I) vs. $8.35(B-I)]$ and 5 min [9.75 (A-I) vs. 9.45 (B-I)] were statistically significantly different between Group A-I and Group B-I (1 min: $P=0.028,5 \mathrm{~min}$ :
$P=0.024)$. Values after $10 \mathrm{~min}$ did not differ significantly. Arterial and venous umbilical $\mathrm{pH}$ values were likewise comparable and did not differ in a statistically significant manner between the study groups. Intervention rates, such as Kristeller maneuver, amniotomy or epidural anesthesia, did not differ significantly between the study groups. As shown in Table 5, the prevalence of episiotomy did not differ significantly between Group A-I and B-I (A-I and B-I): Episiotomy was performed in eight patients in Group A-I and in nine patients in the Group $B-I$. An intact perineum was observed in nine patients in Group A-I and in 14 patients in Group B-I. This difference was not significant, but showed a tendency $(P=0.072$, Table 5).

To further assess perineal outcome dependent on the obstetric gel use, women with Kristeller maneuver were also included into the analysis, and with their admission, 
Table 3 Labor durations of Group A-I and Group B-I: spontenous deliveries in occipito-anterior position without interventions such as $\mathrm{C}$-section, vaginal operative procedures and Kristeller maneuver.

\begin{tabular}{lcccccc}
\hline & A-I Stage I & B-I Stage I & A-I Stage II & B-I Stage II & A-I Stage I \& II & B-I Stage I \& II \\
\hline Sample size (n) & 37 & 37 & 37 & 37 & \multicolumn{1}{c}{37} & 37 \\
Mean & 208.92 & 186.35 & 88.14 & 61.78 & 297.05 & 248.14 \\
Standard deviation (SD) & 125.48 & 137.90 & 60.51 & 36.40 & 130.31 & 156.06 \\
Standard error of mean (SEM) & 20.63 & 22.67 & 9.95 & 5.98 & 21.42 & 25.66 \\
Lower 95\% conf. limit & 167.08 & 140.37 & 67.96 & 49.64 & 253.60 & 196.10 \\
Upper 95\% conf. limit & 250.75 & 232.33 & 108.31 & 73.91 & 340.50 & 300.17 \\
Minimum & 35.00 & 30.00 & 16.00 & 17.00 & 52.00 & 75.00 \\
Median (50 & 165.00 & 140.00 & 78.00 & 56.00 & 284.00 & 202.00 \\
Maximum & 520.00 & 530.00 & 272.00 & 155.00 & 536.00 & 685.00 \\
\hline
\end{tabular}

Table 4 Differences in labor durations, Group A-I vs. Group B-I.

\begin{tabular}{|c|c|c|c|c|c|c|c|}
\hline & $\mathrm{n}$ & $\begin{array}{l}\text { Labor } \\
\text { stage } \\
\text { in min }\end{array}$ & $\begin{array}{l}\text { Mean } \\
\text { reduction }\end{array}$ & $\begin{array}{l}\text { Median } \\
\text { reduction } \\
\text { in min }\end{array}$ & $\begin{array}{l}\text { Mean reduction } \\
\text { in } \%\end{array}$ & $\begin{array}{l}\text { Median reduction } \\
\text { in } \%\end{array}$ & P-value \\
\hline Group A-I vs. B-I & 74 & 1 & 22.57 & 25.00 & 10.80 & 15.15 & n.s. \\
\hline Group A-I vs. B-I & 74 & II & 26.36 & 22.00 & 29.91 & 28.21 & 0.026 \\
\hline Group A-I vs. B-I & 74 & $|\&| \mid$ & 48.91 & 82.00 & 16.47 & 28.87 & n.s. \\
\hline
\end{tabular}

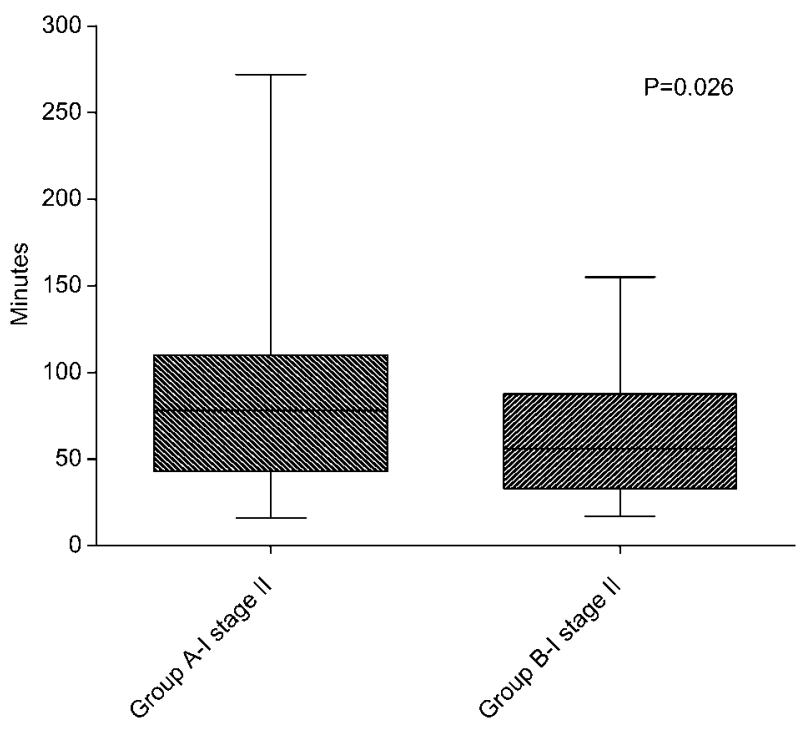

Figure 1 Duration of stage II labor in Groups A-I and B-I.

Groups A-II and Group B-II were formed. As an indicator of perineal protection, intact perineum rates were compared with perineal lacerations. Episiotomies were not referenced. Comparing Group A-II with Group B-II the rate of intact perineum increased by $15 \%$ with the obstetric gel use. This difference was statistically significant $(P=0.024$, Table 5).

The grades of the perineal lacerations did not differ significantly among the study groups: In Group A-II the mean perineal lesion grades were $1.66 \pm 0.48$ (median 2) compared to $1.62 \pm 0.71$ (median 1.5) in Group B-II. In the group with obstetric gel use, the highest laceration reported was grade 3 (twice), whereas in the group without gel, the highest reported laceration grade was grade 2. There was no significant difference in the prevalence of EDA (epidural anesthesia) between the study groups A-II and B-II (data not shown).

Average gel use in Group B was 24.3 1.2 (SEM) mL. The amount of obstetric gel use did not depend on interventions, such as vacuum extraction, forceps extraction, Kristeller, EDA (epidural anesthesia) or amniotomy.

Until the time of discharge from the hospital, possible maternal or neonatal side effects caused by the obstetric gel were assessed by the midwives and by the physicians. The follow-up spans an average of three postnatal days. Among the 94 cases in Group B, neither the midwives nor the obstetricians reported adverse events or side effects potentially associated with the use of the obstetric gel. The use of the obstetric gel did not nega-

Table 5 Perineal integrity in spontaneous deliveries without C-section or vaginal operative procedures.

\begin{tabular}{llllll}
\hline & $\mathrm{n}$ & Episiotomy & Laceration & Intact & Intact rate in \% \\
\hline $\mathrm{P}=0.072$ & & & & & 9 \\
$\quad$ Group A-I & 37 & 8 & 20 & 14 & 24.32 \\
$\quad$ Group B-I & 37 & 9 & 14 & & 37.84 \\
$\mathrm{P}=0.024$ & & 12 & 24 & 10 & 21.74 \\
$\quad$ Group A-II & 46 & 15 & 16 & 18 & 36.73 \\
Group B-II & 49 & & & & \\
\hline
\end{tabular}


tively influence vaginal operative procedures. No negative influence was seen by switching to cesarean section or by the use of electrosurgery.

\section{Discussion}

Friction force has been widely identified as an important opposing force to vaginal childbirth $[4,11,14,15,17$, $19,20,22]$, being influenced by parity and being modified by reducing the friction coefficient by a lubricant. The ancient Greek, Chiron, promoted the use of olive oil and water to facilitate the delivery of a horse in the $4^{\text {th }}$ century $\mathrm{BC}$, a procedure established today as a gold standard in veterinary medicine [1]. To the best of our knowledge, this is the first randomized controlled trial that evaluates the effects of a specially-formulated obstetric gel, used in accordance with the veterinary procedure with labor facilitation and perineal protection.

In women undergoing vaginal delivery without interventions, such as $\mathrm{C}$-sections, vaginal operative procedures or Kristeller maneuver, the use of the obstetric gel did shorten the second stage of labor by 30\% (26 min), in a statistically significant and clinically meaningful manner $(P=0.026)$. The EDA rates did not differ significantly between the study groups. Labor stage I and total labor duration were not significantly reduced. Our results showing a significantly shortened second stage of labor are supported by the group of Stamp et al. who also demonstrated, to a lesser extent, a significant reduction in the second stage of labor by 11 min through perineal massage [23].

Our results did not show a significant change in secondary outcome parameters, such as intervention rates and maternal and neonatal outcomes. However, in women undergoing vaginal deliveries without interventions, Apgar values after 1 and 5 min were significantly lower in the group with obstetric gel use. Although significant, these differences were not clinically meaningful and can be explained by the obstetric gel influencing the visual and tactile appearance of the newborn, important components of the Apgar score.

In women experiencing vaginal deliveries without interventions, such as cesarean section or vaginal operative procedure, the use of the obstetric gel showed a statistically significant increase in the perineal integrity $(P=0.024)$. This finding has not yet been reported by other authors. Neither Stamp et al. [23] nor Albers et al. [3] could demonstrate such an effect in their randomized trials. This newly demonstrated effect of perineum protection can be attributed either to the special properties of the obstetric gel, or to the different application procedure starting at early first stage of labor in this trial. Stamp et al. and Albers et al. did investigate the effect of perineal massage on late second stage of labor with an ordinary lubricant used for vaginal examinations $\left(\mathrm{K}-\mathrm{Y}\right.$ Gel $\left.{ }^{\circledR}\right)$, Johnson and Johnson (New Brunswick, USA). In contrast to this gel, the polyacrylic acid component of the obstetric gel used in this study is known to have one of the highest mucoadhesive properities, and is able to induce a mucoadhesive film onto the birth canal that eventually leads to the newly seen perineal protecting effect. This effect may be further supported by the different application procedure used in this trial which started at early first stage of labor, compared to the perineum massage investigated by Stamp and Albers and their respective coworkers.

In this trial, no adverse events or side effects potentially linked with the use of the obstetric gel, such as allergic reactions, infections, or newborn aspiration, have been reported by the midwives or physicians. These findings suggest that the use of the obstetric gel for labor facilitation starting at early first stage of labor can be regarded as safe in humans.

The systematic use of the obstetric gel in vaginal childbirth did show significant effects in shortening the second stage of labor and in perineal protection. To further investigate the impact of the obstetric gel on secondary outcome parameters, such as intervention rates and maternal and neonatal outcomes, larger clinical trials will have to be carried out.

\section{Acknowledgements}

This work was financially supported by the HCB Happy Childbirth Holding \& Foundation, Switzerland and Farco Pharma $\mathrm{GmbH}$, Germany.

\section{References}

[1] Ahlers D. Rechtsfragen in der Geburtshilfe. In: Richter/ Goetze Tiergeburtshilfe. Paul Parey Verlag, Berlin und Hamburg 1993. p. 614.

[2] Albers LL, Schiff M, Gorwoda JG. The length of active labor in normal pregnancies. Obstet Gynecol. 1996;87: 355-9.

[3] Albers LL, Sedler KD, Bedrick EJ, Teaf D, Peralta P. Midwifery care measures in the second stage of labor and reduction of genital tract trauma at birth: a randomized trial. J Midwifery Womens Health. 2005;50:365-72.

[4] Andrews CM. Changing fetal position through maternal posturing. Birth Defects Orig Artic Ser. 1981;17:85-96.

[5] Beckmann MM, Garrett AJ. Antenatal perineal massage for reducing perineal trauma. Cochrane Database Syst Rev. 2006, Issue 1.

[6] Cheng YW, Hopkins LM, Caughey AB. How long is too long: does a prolonged second stage of labor in nulliparous women affect maternal and neonatal outcomes? Am J Obstet Gynecol. 2004;191:933-8.

[7] Cheng YW, Hopkins LM, Russell KL, Aaron BC. Duration of the second stage of labor in multiparous women: maternal and neonatal outcomes. Am J Obstet Gynecol. 2007; 196:585-7.

[8] Christianson LM, Bovbjerg VE, McDavitt EC, Hullfish KL. Risk factors for perineal injury during delivery. Am J Obstet Gynecol. 2003;189:255-60. 
[9] Donnelly V, Fynes M, Campbell D, Johnson H, O'Connell PR, O'Herlihy C. Obstetric events leading to anal sphincter damage. Obstet Gynecol. 1998;92:955-61.

[10] Eason E, Labrecque M, Wells G, Feldman P. Preventing perineal trauma during childbirth: a systematic review. Obstet Gynecol. 2000;95:464-71.

[11] Furuya H, Hashimoto T, Kokuho K, Kino H, Fukamauchi K. Pressures on the human fetus during labor-intrauterine and on the fetal head. Nippon Sanka Fujinka Gakkai Zasshi. 1981;33:2173-81.

[12] Johanson R. Perineal massage for prevention of perineal trauma in childbirth. Lancet. 2000;355:250-1.

[13] Kearney R, Miller JM, Ashton-Miller JA, DeLancey JO. Obstetric factors associated with levator and muscle injury after vaginal birth. Obstet Gynecol. 2006;107:144-9.

[14] Lindgren L, Holmlund D. Friction between the fetal head and uterine wall during normal labor and lower uterine spasm. Am J Obstet Gynecol. 1969;103:939-41.

[15] Manassiev N. Head-to-cervix force: an important physiological variable in labor. Br J Obstet Gynaecol. 1997;104: 272-3.

[16] Mant J, Painter R, Vessey M. Epidemiology of genital prolapse: observations from the Oxford Family Planning Association Study. Br J Obstet Gynaecol. 1997;104: 579-85.

[17] Martius G. Roederersch Kopfhaltung als Folge einer Weichteilanomalie. Ein Beitrag zur Bedeutung der Weichteilanomalie. Geburtshilfe Frauenheilkd. 1970;30:356-61.
[18] Meyer S, Hohlfeld P, Achtari C, Russolo A, De Grandi P. Birth trauma: short and long term effects of forceps delivery compared with spontaneous delivery on various pelvic floor parameters. Br J Obstet Gynaecol. 2000;107:1360-5.

[19] Moolgaoker AS, Ahamed SO, Payne PR. A comparison of different methods of instrumental delivery based on electronic measurements of compression and traction. Obstet Gynecol. 1979;54:299-309.

[20] Rempen A, Kraus M. Pressures on the fetal head during normal labor. J Perinat Med. 1991;19:199-206.

[21] Rortveit G, Hannestad YS, Daltveit AK, Hunskaar S. Ageand type-dependent effects of parity on urinary incontinence: the Norwegian EPINCONT study. Obstet Gynecol. 2001;98:1004-10.

[22] Sallam HN, Abdel-Dayem A, Sakr RA, Sallam A, Loutfy I. Mathematical relationships between uterine contractions, cervical dilatation, descent and rotation in spontaneous vertex deliveries. Int J Gynaecol Obstet. 1999;64:135-9.

[23] Stamp G, Kruzins G, Crowther C. Perineal massage in labour and prevention of perineal trauma: randomised controlled trial. Br Med J. 2001;322:1277-80.

[24] Sultan AH, Kamm MA, Hudson CN, Thomas JM, Bartram $\mathrm{Cl}$. Anal-sphincter disruption during vaginal delivery. $\mathrm{N}$ Engl J Med. 1993;329:1905-11.

Received August 1, 2007. Revised September 5, 2007. Accepted October 20, 2007. Previously published online January 23, 2008. 